\title{
Late prevertebral abscess following anterior cervical plating: the missing screw
}

\author{
J.F. Martínez-Lage*,**; M. Felipe-Murcia* and L. Martínez-Lage Azorín***
}

*Servicio de Neurocirugía. Hospital Virgen de la Arrixaca. Murcia. **Grupo de Neurología y Neurocirugía Experimental (NYNE). Facultad de Medicina. Universidad de Murcia. Campus de Espinardo. Murcia. ***Servicio de Microbiología. Hospital Morales Meseguer. Murcia. Spain.

\section{Summary}

A 51-year-old man underwent a C5-C7 anterior decompression and fusion. Six years later the patient complained of dysphagia caused by displacement of the cervical plate. One week after the scheduled removal of the implanted material, the patient developed a painful cervical swelling and fever. His cervical radiographs showed that a screw was missing compared to previous studies. Computerized tomography showed a large prevertebral abscess anterior to C4-C7. He underwent emergency surgical drainage of the abscess that was followed by total recovery. This report is aimed at describing this unusual complication of cervical instrumentation and to briefly review its pathogenesis and management options.

KEY WORDS: Prevertebral cervical abscess. Cervical spine. Cervical fusion instrumentation. Esophageal perforation. Complications of spinal fusion.

Absceso prevertebral tardío tras fusión cervical instrumentada: el tornillo ausente

\section{Resumen}

Un hombre de 53 años que había sido operado de descompresión cervical anterior C5-C7 con fijación mediante placa y tornillos, se presentó 6 años después con disfagia atribuida a compresión del esófago por desplazamiento anterior de la placa, lo que motivó la retirada programada de todo el implante. Una semana más tarde, el paciente acudió a nuestro hospital con fiebre y tumoración dolorosa en la parte anterior del cuello. Las radiografías mostraron la ausencia de uno de los tornillos y la tomografía computerizada evidenció un absceso prevertebral cervical C4-C7. El absceso fue drenado de urgencia, y el paciente se recuperó totalmente. Los autores describen esta complicación

Recibido; 1-02-06. Aceptado: 24-04-06 infrecuente de la instrumentación cervical y revisan su patogenia y las opciones de tratamiento.

PALABRAS CLAVE: Absceso prevertebral cervical. Columna cervical. Fijación cervical instrumentada. Perforación esofágica. Complicaciones de la fusión espinal.

\section{Introduction}

Anterior cervical spine procedures are widely used for stabilization and fixation of the vertebral column in degenerative, neoplastic and traumatic conditions. Cloward's and Smith-Robinson's techniques are well-known fusion procedures of the cervical spine with bone grafts ${ }^{3,11}$. During the last decade there has been a growing development of the methods employed for spinal stabilization and fusion by means of a variety of surgical techniques that include the placement of plates and screws, grouped under the name of spinal instrumentation. Early minor complications include dysphagia that is frequently attributed to cervical soft tissues swelling or hematoma. Other complications include early and late esophageal perforation ${ }^{13}$. Asymptomatic migration and extrusion of grafts or screws and plate through the mouth or bowels has seldom been reported ${ }^{3,6,7}$. More infrequently, grafts, screws or whole plate displacement have also been reported to produce pharyngo-esophageal injuries ${ }^{10}$. Life threatening complications include prevertebral abscess, airway obstruction, mediastinitis and carotid artery rupture ${ }^{5,12-14}$. The authors' aim is to report the case of a patient who developed a prevertebral cervical abscess following the removal of the screws and plate placed 6 years before. We also briefly review some previous publications on these uncommon complications and discuss the probable mechanism that leads to these severe post-surgical injuries.

\section{Case report}

A 51-year-old man was admitted with neck pain and swelling of 24 hours of evolution. In 1999 he had undergone, at another institution, a fusion procedure that invol- 


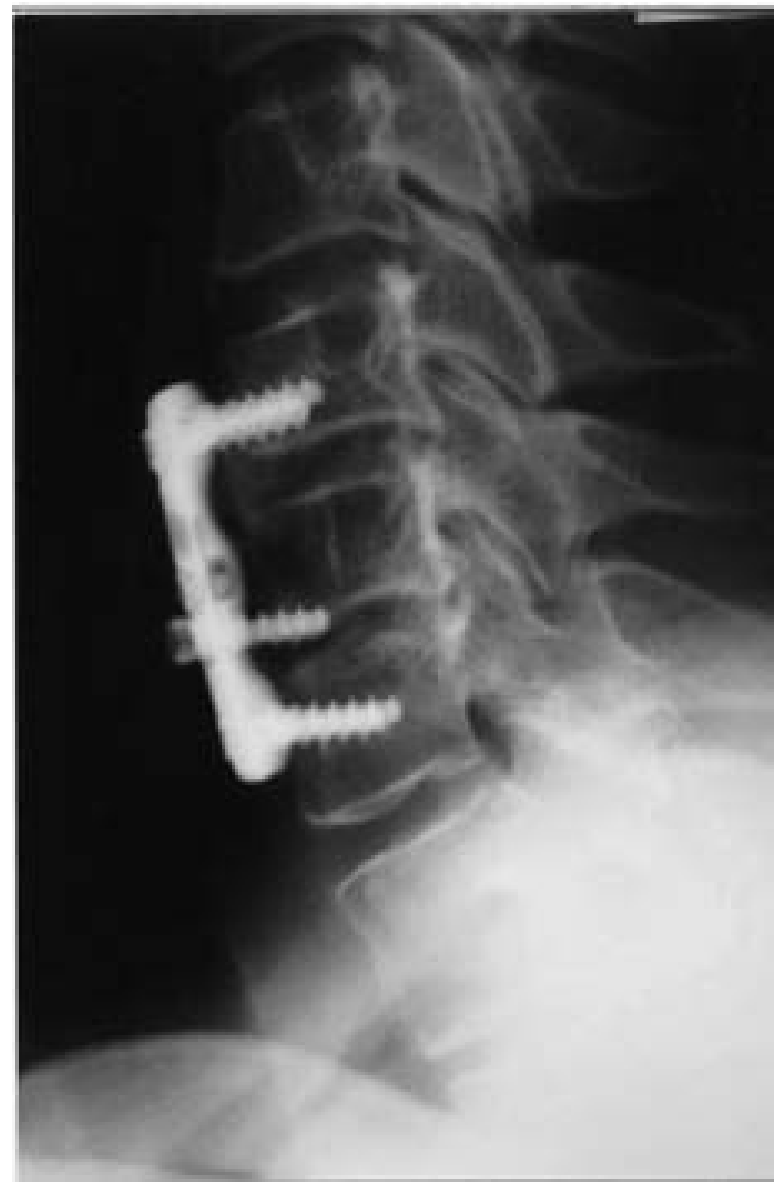

Figure 1. Cervical radiograph of the patient showing anterior displacement of the central screw

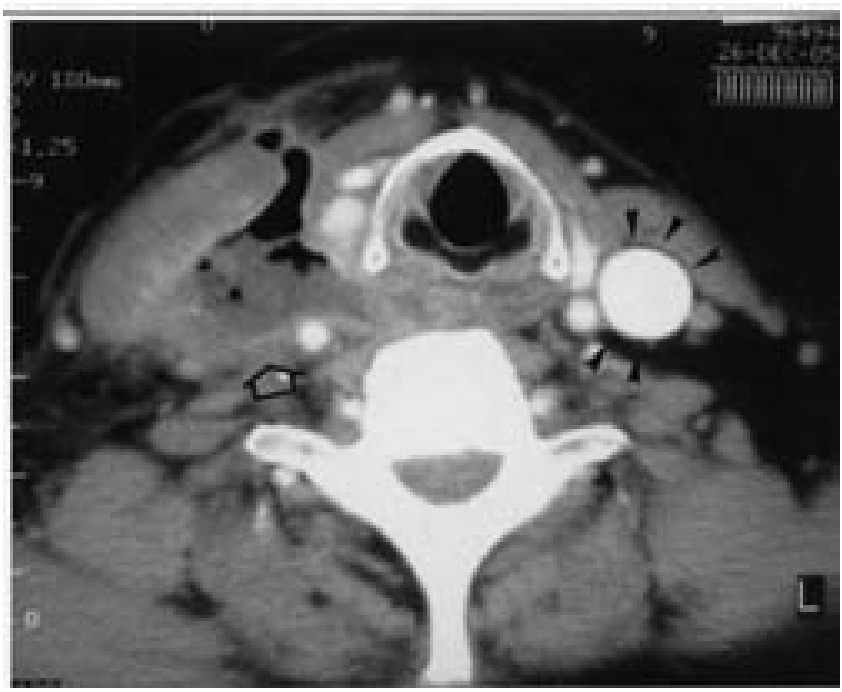

Figure 3. Computerized tomography scan showing a right cervical prevertebral abscess (arrow). There is air within the abscess cavity. Note the absence of filling of the right jugular vein together with the engorgement of the left one (arrowheads).
2007; 18: 111-114

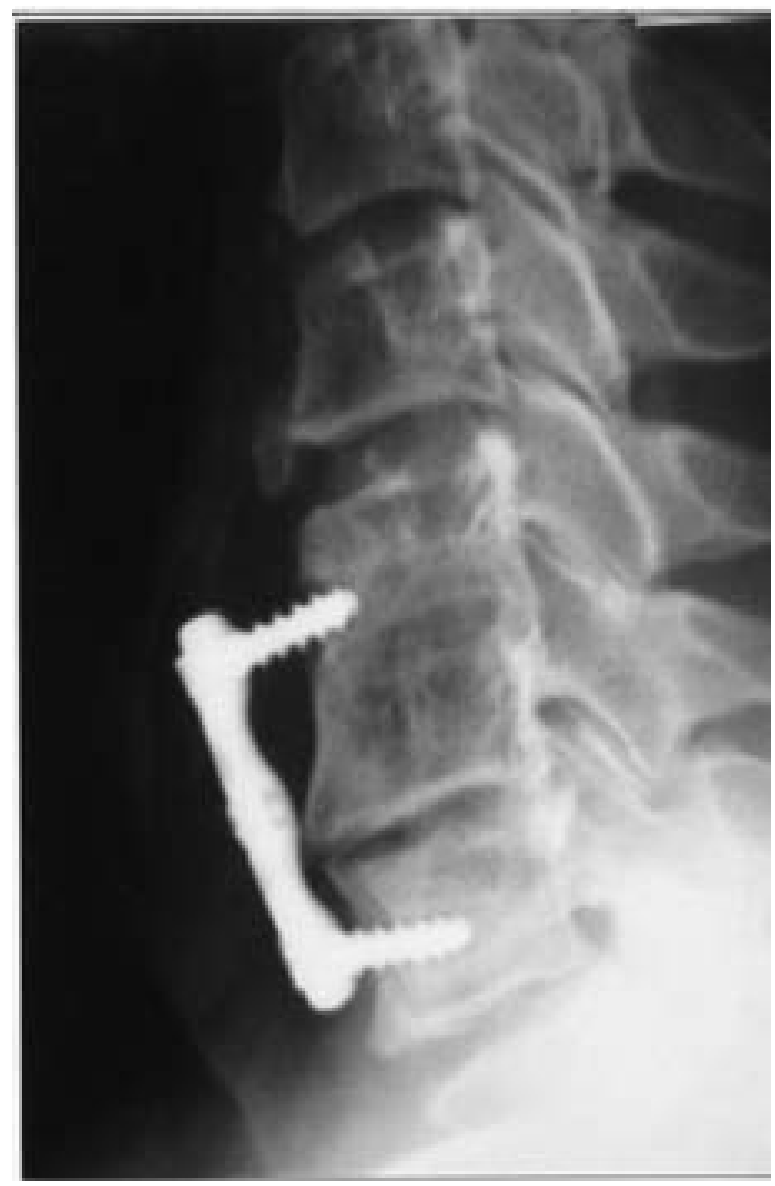

Figure 2. Radiographs obtained 6 years after cervical fusion showing displacement of the fusion plate and the "missing screw"

ved the placement of a C5-C6 bone graft and of plate and screws from C5 to C7. A control cervical spine radiograph had shown a satisfactory bone fusion and an anteriorly displaced screw (Fig. 1). Six years later, the patient started to complain of dysphagia that was attributed to the partial dislocation of the implant (Fig. 2). At this time, it was noted that the central screw was missing. Esophagoscopy and isotopic bone scan were normal, and chest and abdomen radiographs failed to show the displaced screw. Five months later, he underwent scheduled removal of the instrumentation components. On hospital admission, 1 week after this surgery, the patient noted cervical pain and rigidity together with increasing dysphagia. Past medical history was irrelevant.

On admission the patient appeared fully conscious, and his neurological examination was normal. There was a reddened and painful swelling on the right side of his neck and his temperature was $40^{\circ} \mathrm{C}$. Complementary investigations showed 13000 leukocytes per $\mathrm{mm}^{3}$ and a Creactive protein value of 24 (normal $<0.5$ ). A computerized 
tomography of the patient's neck disclosed a prevertebral abscess $4.5 \mathrm{~cm}$ in diameter from C4 to C7 that contained some bubbles of air (Fig. 3).

On December 26, 2005, the patient was submitted to emergency drainage of the prevertebral abscess. After skin opening, some $40 \mathrm{ml}$ of pus came out spontaneously. During the procedure, the walls of the abscess cavity were inspected but no esophageal perforation was seen. The surgical bed was thoroughly washed with saline noting no leakage of air. Finally, the wound was loosely closed in layers leaving a Penrose drain in place.

Culture of the purulent material yielded a group-F betahemolytic streptococcus. The patient was given a 2-week course of amoxicillin and ciprofloxacin that was followed by total recovery. Additional studies aimed at detecting a probable perforation of the esophagus were negative, as were the investigations done for ruling out other possible sources of infection. Repeat radiographs of the patient's cervical spine showed a satisfactory union of the fused vertebrae.

\section{Discussion}

Since the initial reports of Cloward and Smith \& Robinson on cervical fusion with grafts of autologous bone, the use of the anterior approach for management of diverse pathological conditions (degenerative, traumatic or neoplastic diseases) has gained widespread acceptance ${ }^{3,11}$. However, the most effective method for decompression and stabilization of patients with cervical spine diseases, especially those with the most complex disorders, remains controversial $^{9}$. Most degenerative cervical disorders can be managed surgically with an anterior or posterior approach alone $^{9}$. In the last decade we have witnessed an upsurge in the use of methods of spinal fusion with utilization of a variety of plates and screws, grouped under the name of spinal instrumentation ${ }^{1}$. Some problems of the new instrumentation techniques of the neck comprise progressive kyphosis, pseudoarthrosis, graft dislodgement, plate breakdown and halo vest-related complications. In a recent review of 72 patients submitted to anterior and posterior fixation cervical procedures, Schultz $\mathrm{Jr}$ et al. report early complications in $32 \%$ of the cases, most of them of transient character ${ }^{9}$. The long-term complication rate in this series was of only $5 \%$, nearly all of them related to the anterior component of the operation ${ }^{9}$. Transient complications included hoarseness, dysphagia, worsening of myelopathy, donor graft site infection and cerebrospinal fluid leak ${ }^{9}$. Permanent sequelae of these patients consisted of superior laryngeal nerve injury and partial dysphagia in one case each ${ }^{9}$. These authors specifically state not having experienced cases with plate or screw fracture or with graft extrusion ${ }^{9}$. A main cause of morbidity of these procedures, especially those of the anterior approach, is associated to the migration of the graft or plates. Graft dislodgement occurs between $6-10 \%$ of the patients ${ }^{9}$.

Some authors have documented the spontaneous elimination of screws through the mouth ${ }^{4,6,7}$ or through the gastrointestinal tract ${ }^{2}$, or even the extrusion of the graft and the whole fixation device without further consequences ${ }^{10}$. Talmi et al. have documented 6 cases of prevertebral cervical abscess of early presentation after surgery in tetraplegic patients submitted to anterior fusion ${ }^{12}$. In another instance, the prevertebral abscess lead to severe upper airway obstruction that required immediate tracheostomy ${ }^{14}$. Vrouenraets et al. have also published two cases of esophageal perforation, occurring one at the immediate postoperative period and the other several years after spinal fusion, the latter ending in severe bleeding from erosion of the common carotid artery ${ }^{13}$.

Gaudinez et al. ${ }^{5}$ have reported a large series of esophageal perforation related to cervical fusion procedures. In 34 of 44 the fusion was undertaken for treatment of cervical fractures, 28 with plate and screws ${ }^{5}$. Cervical osteomyelitis or neck abscess developed in 22 cases $^{5}$. Forty-two patients required surgical repair of the esophageal injury ${ }^{5}$. Clinical symptomatology was of neck and throat pain, dysphagia, hoarseness and aspiration. Common clinical findings consisted of elevated temperature, localized induration, neck tenderness, crepitus or subcutaneous air in the neck, tachycardia, and blood in the nasogastric tube. In the case or prevertebral cervical abscess due to esophageal perforation, the infecting organisms are usually those belonging to the normal bacterial flora of the pharyngo-esophageal tract and include several types of staphylococci, streptococci, neisseriae, clostridium etc. Often, the infection is of mixed bacterial nature ${ }^{12}$. In our patient, the causative organism was an F-group beta-hemolytic streptococcus. Further characterization of the infecting organism was very complex, most probably being a streptococcus anginosum ${ }^{8}$.

Diagnostic studies include complete cell blood count, erythrocyte sedimentation rate, C-reactive protein, plain radiographs of the neck and computerized tomography or magnetic resonance to depict the presence of osteomyelitis or prevertebral abscess. Cervical x-ray films of our patient were most useful to depict the displacement of the plate and the missing screw. Radiographs of the chest and abdomen allowed ruling out the presence of the foreign body along the gastrointestinal tract. Esophagoscopy was indicated to search a possible esophageal perforation.

There is no agreement regarding management of these uncommon complications. Gaudinez et al..$^{5}$ recommend prompt surgical repair of esophageal perforation if it exists, while others have followed a conservative attitude in regard to the removal of the plate and screws and for treatment of the esophageal injury $y^{6,7,10}$. In instances of prevertebral cer- 
vical abscess, as that of our patient, surgical drainage of the purulent collection is mandatory both for bacteriological diagnosis and for treatment ${ }^{12,14}$.

Finally, we would like to submit the reader to a recent editorial on "failed back surgery patients" in which the author critically comments the use (and abuse) of these newly introduced instrumentation techniques ${ }^{1}$. Apparently, spinal medicine is producing patients with failed back surgery syndrome at an alarming rate ${ }^{1}$. Probably, some surgical complications of spinal instrumentation might be avoided by a more correct utilization of the new techniques and by following more strict indications for spinal fusion. Unfortunately, as it happens in other fields of medicine, guidelines for the use of spinal fixation procedures are still uncompleted.

\section{Conclusions}

We report a case of delayed prevertebral abscess after cervical instrumentation. Most probably, the abscess formed as a consequence of perforation of the esophagus caused by a displaced screw ("the missing screw"). We suggest removing the metallic implants when they become abnormally movable to avoid the "suspension blade effect", a complication that usually starts because of insufficient contact between the plate and the underlying bone $e^{4}$. The successful management of esophageal perforation and its complications, as neck abscess, depends on the awareness of this possibility by the physicians, prompt diagnosis and on the immediate institution of treatment ${ }^{5}$.

\section{References}

1. Burton, C.V.: Failed back surgery patients: the alarm bells are ringing. Surg Neurol 2006; 65: 5-6.

2. Châtaigner, H., Gangloff, S., Onimus, M.: Elimination spontanée de vis d'ostéosynthèse cervicale antérieure par les voies naturelles. A propos d'un cas. Rev Chir Orthop Reparatrice Appar Mot 1997; 83: 78-82.

3. Cloward, R.: The anterior approach for removal of ruptured cervical disks. J Neurosurg 1958; 15: 602-614.

4. Finiels, P.J., Hernández, G., Sabatier, P., Frerebeau, P.: Delayed esophageal perforation after cervical osteosynthesis. Case illustration. J Neurosurg (Spine 1) 2000; 92: 123.

5. Gaudinez, R.F., English, G.M., Gebhard, J.L., Donald- son D.H., Brown, C.W.: Esophageal perforations after anterior cervical surgery. J Spinal Disord 2000; 13: 77-84.

6. Geyer, T.E., Foy, M.A.: Oral extrusion of a screw after anterior cervical spine plating. Spine 2001; 26: 1814-1816.

7. Pompili, A., Canitano, S., Caroli, F., Caterino, M., Crecco, M., Raus, L., Occhipinti, E.: Asymptomatic esophageal perforation caused by late screw migration after anterior cervical plating: report of a case and review of relevant literature. Spine 2002; 27: E499-502.

8. Ruoff, K.L.: Streptococcus anginosus (streptococcus milleri): the unrecognized pathogen. Clin Microbiol Rev 1988; 1: 102-108.

9. Schultz, K.D. Jr., McLaughlin, M.R., Haid, R.W. Jr., Comey, C.H., Rodts G.E. Jr., Alexander, J.: Single-stage anterior-posterior decompression and stabilization for complex cervical spine disorders. J Neurosurg (Spine 2) 93: 214221.

10. Sharma, R.R., Sethu, A.U., Lad, S.D., Turel, K.E., Pawar, S.J.: Pharyngeal perforation and spontaneous extrusion of the cervical graft with its fixation device: a late complication of C2-C3 fusion via anterior approach. J Clin Neurosci 2001; 8: 464-468.

11. Smith, G., Robinson, R.: The treatment of certain cervical-spine disorders by anterior removal of the intervertebral disc and interbody fusion. J Bone Joint Surg (Am) 1958; 40:607-623.

12. Talmi, Y.P., Knoller, N., Dolev, M., Wolf, M, Simansky, D.A., Keller, N., et al.: Postsurgical prevertebral abscess of the cervical spine. Laryngoscope 2000; 110: 1137-1141.

13. Vrouenraets, B.C., Been, H.D., Brower-Mladin, R., Bruno, M., van Lanschot, J.J.B.: Esophageal perforation associated with cervical spine surgery: report of two cases and review of the literature. Dig Surg 2004; 21: 246-249.

14. Wong, D.T., Fehlings, M.G., Massicotte, E.M.: Anterior cervical screw extrusion leading to acute upper airway obstruction: case report. Spine 2005; 30:E683-686.

Martínez-Lage, J.F.; Felipe-Murcia; M.; Martínez-Lage Azorín, L.: Late prevertebral abscess following anterior cervical plating: the missing screw. Neurocirugía 2007; 18: 111-114.

Correspondencia postal: Juan F. Martínez-Lage. Servicio Regional de Neurocirugía. Hospital Universitario Virgen de la Arrixaca. E-30120 El Palmar. Murcia. 